\title{
BMJ Global Health Cost-effectiveness of different strategies for screening and treatment of Strongyloides stercoralis in migrants from endemic countries to the European Union
}

\author{
Philip Erick Wikman-Jorgensen (D) ,1,2 Jara Llenas-Garcia, ${ }^{3,4}$ Jad Shedrawy, ${ }^{5}$ \\ Joaquim Gascon, ${ }^{6}$ Jose Muñoz, ${ }^{6}$ Zeno Bisoffi, ${ }^{7,8}$ Ana Requena-Mendez ${ }^{9,10}$
}

To cite: Wikman-Jorgensen PE, Llenas-Garcia J, Shedrawy J, et al. Cost-effectiveness of different strategies for screening and treatment of Strongyloides stercoralis in migrants from endemic countries to the European Union. BMJ Global Health 2020;5:e002321. doi:10.1136/ bmjgh-2020-002321

\section{Handling editor Lei Si}

- Additional material is published online only. To view, please visit the journal online (http://dx.doi.org/10.1136/ bmjgh-2020-002321).

Received 16 January 2020 Revised 7 April 2020 Accepted 8 April 2020

\section{Check for updates}

(c) Author(s) (or their employer(s)) 2020. Re-use permitted under CC BY-NC. No commercial re-use. See rights and permissions. Published by BMJ.

For numbered affiliations see end of article.

Correspondence to Dr Philip Erick WikmanJorgensen;

wikman.philip@gmail.com

\section{ABSTRACT}

Background The best strategy for controlling morbidity due to imported strongyloidiasis in migrants is unclear. We evaluate the cost-effectiveness of six possible interventions.

Methods We developed a stochastic Markov chain model. The target population was adult migrants from endemic countries to the European Union; the time horizon, a lifetime and the perspective, that of the health system. Average and incremental cost-effectiveness ratios (ACER and ICER) were calculated as 2016 EUR/life-year gained (LYG). Health interventions compared were: base case (no programme), primary care-based presumptive treatment (PCPresTr), primary care-based serological screening and treatment (PCSerTr), hospital-based presumptive treatment (HospPresTr), hospital-based serological screening and treatment (HospSerTr), hospital-based presumptive treatment of immunosuppressed (HospPresTrim) and hospital-based serological screening and treatment of the immunosuppressed (HospSerTrim). The willingness to pay threshold (WTP) was $€ 32$ 126.95/LYG.

Results The base case model yielded a loss of 2 486708.24 life-years and cost EUR 3238 393. Other interventions showed the following: PCPresTr: 2488 095.47 life-years ( $\Delta 1387.23 \mathrm{LYG})$, cost: EUR 8194 563; ACER: EUR 3573/LYG; PCSerTr: 2488085.8 lifeyears ( $\triangle 1377.57 \mathrm{LYG})$, cost: EUR 207679 077, ACER: EUR 148 407/LYG; HospPresTr: 2488046.17 life-years ( 1 1337.92LYG), cost: EUR 14559 575; ACER: EUR 8462/ LYG; HospSerTr: 2488024.33 life-years ( $\triangle 1316.08 L Y G)$; cost: EUR 207734 073; ACER: EUR 155 382/LYG; HospPresTrim: 2488093.93 life-years, cost: EUR 1105 483; ACER: EUR -1539/LYG (cost savings); HospSerTrim: 2 488073.8 life-years ( $\triangle 1365.55 \mathrm{LYG}$ ), cost: EUR 4274 239; ACER: EUR 759/LYG. One-way and probabilistic sensitivity analyses were undertaken; HospPresTrim remained below WTP for all parameters' ranges and iterations.

Conclusion Presumptively treating all immunosuppressed migrants from areas with endemic Strongyloides would generate cost savings to the health system.

\section{Key questions}

What is already known?

- To date, no study has evaluated the costeffectiveness of different strategies for screening and treating strongyloidiasis in people migrating from endemic countries to Europe.

What are the new findings?

- Presumptively treating immunosuppressed migrants from endemic areas, without screening or testing was a cost-saving strategy compared with the current base-case scenario.

What do the new findings imply?

- The results will have a direct impact on clinical guidelines and public health policy across Europe allowing for cost savings.

\section{BACKGROUND}

Strongyloides stercoralis is an intestinal helminth that can cause strongyloidiasis, a parasitic disease in humans. While this nematode is most prevalent in the tropics and subtropics, its distribution is global, and it can also be found in temperate countries with favourable conditions. $^{1}$

Some estimates suggest that at least 370 million people are infected worldwide, ${ }^{2}$ and a recent systematic review estimated a pooled prevalence of $12.2 \% \quad(95 \%$ CI $9.0 \%$ to $15.9 \%$ ) in migrants from endemic areas residing in non-endemic areas. ${ }^{3}$

Strongyloidiasis frequently presents asymptomatically or with unspecific and mild clinical symptoms stemming from skin penetration (rash, urticaria, larva currens), migration through the body (cough, sore throat, pulmonary infiltrates) and presence in the intestine (abdominal pain and diarrhoea). 
The most serious health risk is the development of disseminated disease or hyperinfection syndrome, which usually occurs in immunosuppressed patients, particularly those using corticosteroids. ${ }^{4}$ However, many other conditions causing immunosuppression (such as leukaemia or transplant) have also been associated with a severe form of the disease, with a reported mortality of up to $62 \% .^{5}$

Enhanced microscopic-based direct techniques, such as agar plate culture or the Baermann method, have improved diagnosis, but their sensitivity is still low because of the intermittent larval excretion and a low parasitic burden. ${ }^{4}$ Due to its accuracy, simplicity and reproducibility, serology is the most widespread and recommended technique used, ${ }^{4}$ having demonstrated a very high sensitivity, although the specificity is lower due to cross-reactions with other helminth infections. In terms of treatment, ivermectin is currently the drug of choice, ${ }^{6}$ with an optimal dosage schedule of a single dose for uncomplicated strongyloidiasis. ${ }^{7}$

Migrants from strongyloidiasis-endemic countries can import the disease to non-endemic areas. There, the disease may remain undetected for long periods of time due to lack of healthcare provider awareness, the unspecific presentation and the ability of the helminth to reproduce indefinitely in the host. ${ }^{8}$ If left untreated, the infection will be lifelong. In addition, the disease can be transmitted in non-endemic areas, for example, through solid organ transplantation. ${ }^{9}$

At the same time, in high-income countries or countries in economic transition, the increasing prevalence of chronic medical conditions and malignancies, combined with the availability of potentially harmful treatments, will likely increase the risk of severe complications from unrecognised chronic $S$. stercoralis infection in immunosuppressed patients. ${ }^{2}$ Routine screening for strongyloidiasis in migrants at high risk of exposure to Strongyloides infection and in immunosuppressed migrants at intermediate risk has been recommended as a strategy to prevent severe complications. ${ }^{10}{ }^{11}$ However, several potential screening strategies could be implemented, so further cost-effectiveness studies are required to better understand and implement the most cost-effective approach.

This study aims to evaluate the cost-effectiveness of six possible public health interventions to address and prevent strongyloidiasis in migrants from endemic areas living in the European Union (EU).

\section{METHODS}

\section{Target population setting and perspective}

The target population of the study was migrants coming from $S$. stercoralis-endemic areas and living in non-endemic areas, specifically, migrants from South America, Central America, the Caribbean, Africa and Asia, and living in Europe. Although some EU countries are considered as endemic for $S$. stercoralis (such as Spain or Italy), the incidence reported is very low and limited to certain population subgroups. Thus, for the purpose of this study we considered all EU countries as non-endemic for the disease. The model was considered representative of the European setting, as the data used in the study originate from studies conducted in the region. Our analysis used a healthcare provider perspective.

\section{Strategies evaluated}

Both hospital-based and primary care-based interventions were evaluated from a health system (provider) perspective. These interventions were agreed on by an internal panel as the most suitable strategies for potential implementation. Six strategies were evaluated against a basecase scenario where no specific intervention is undertaken. This was considered the status quo, in which some cases can be detected through medical check-up when migrants present to the health centre for any reason. The evaluated interventions are as follows.

\section{Primary care-based interventions}

1. Primary care presumptive treatment (PCPresTr): providing presumptive treatment once at a primary care level to all migrants attended for any reason.

2. Primary care serology and treatment (PCSerTr): screening migrants at the primary care level with serology and treating positive cases.

\section{Hospital-based interventions}

1. Hospital-based presumptive treatment (HospPresTr): providing presumptive treatment with ivermectin to migrants attended at hospital for any reason.

2. Hospital-based serology and treatment (HospSerTr): screening migrants at hospital clinic with serology and treating only the positive cases.

3. Hospital-based presumptive treatment of immunosuppressed migrants (HospPresTrim): providing presumptive treatment with ivermectin to immunosuppressed migrants at the hospital level (eg, migrants with an active tumour, starting steroids, HIV infected).

4. Hospital-based serology and treatment of immunosuppressed (HospPresTrim): screening of immunosuppressed migrants at the hospital level with serology and treatment of positive cases.

\section{Cost-effectiveness model}

A compartmental Markov model was considered appropriate to answer the study's research question (figure 1). Due to the chronic nature of strongyloidiasis, a lifetime time horizon was chosen. A 3\% yearly discount rate was applied to both costs and effectiveness. ${ }^{12}$

The model represents a cohort of 100,000 migrants aged 35 years from $S$. stercoralis-endemic countries. These individuals enter the model in one of two health states: infected or not infected with the disease. From there, infected migrants (state 1) can seek outpatient care (state 2) and be diagnosed and treated (state 3). They can then be cured and go to the non-infected patient state (state 4) or fail to achieve a cure and go back to the infected patient state (state 1). If infected migrants are not treated, they can develop disseminated strongyloidiasis 


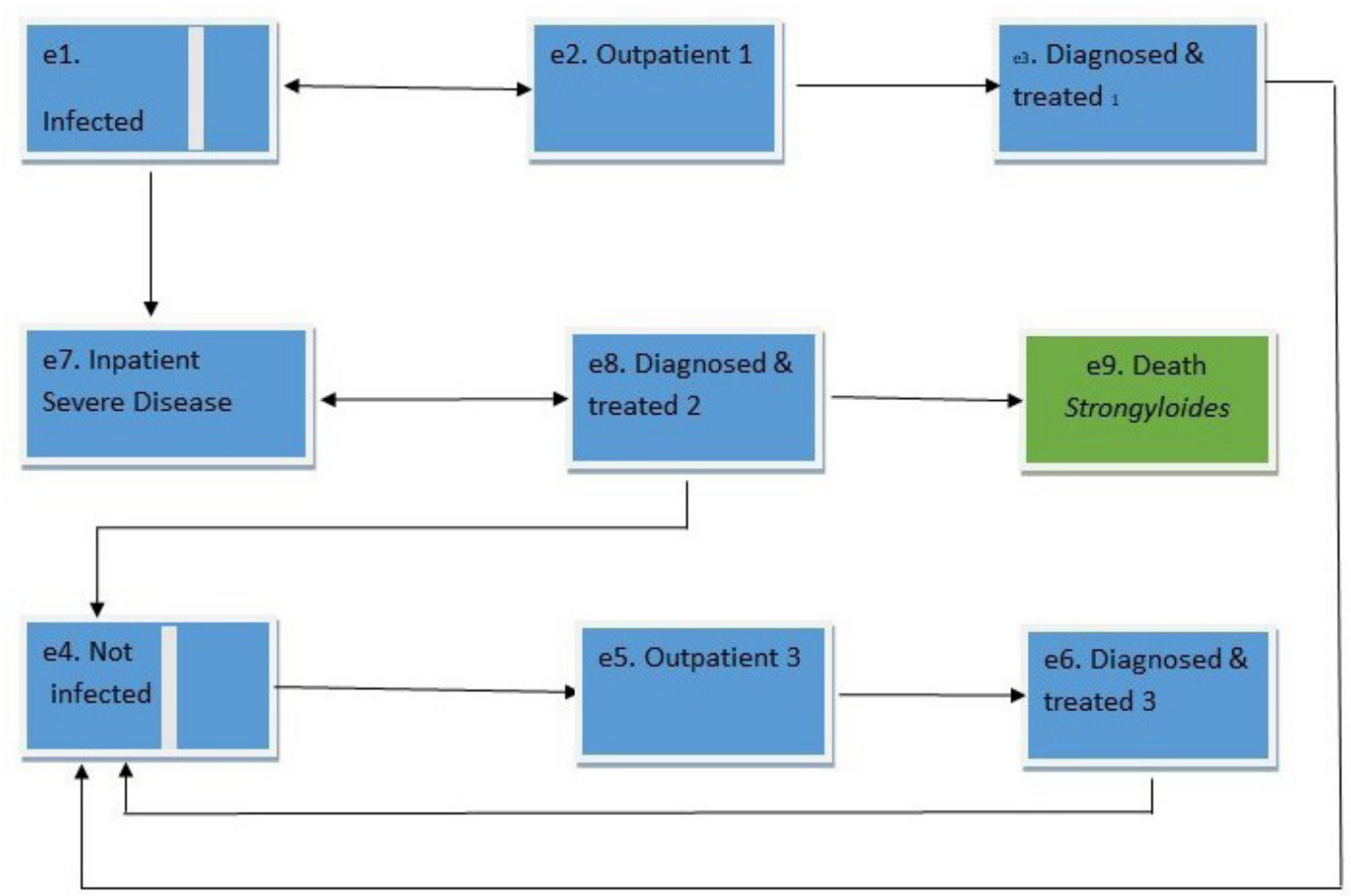

Figure 1 Compartmental Markov model for strongyloidiasis. No arrows to "death other cause" because patients from all states (except from death due to strongyloidiasis) can transition into this state; e1 is divided as patients that transition back from e2 cannot be treated or screened again; e4 is also divided as patients getting cured (ie, not infected) would not be tested or treated again.

and be admitted to hospital (state 7). Then they can be diagnosed and treated (state 8 ), achieving a cure (state 4) or dying (state 9). Non-infected migrants start at the noninfected state (state 4), can seek outpatient care (state 5 ) and get diagnosed and treated as false positive cases (state 6) and go back to the not-infected state (state 4). The model was terminated when all individuals reached the death state.

Several assumptions were built into the model:

1. The composition of the migrant population did not change over time.

2. The percentage of immunosuppressed migrants was constant.

3. Migrants could never be treated twice for strongyloidiasis, nor was the outcome tested.

4. There is no local transmission.

5. The availability of ivermectin was guaranteed.

Online supplementary appendix 1 presents the details of the model as well as its parameters (online supplementary material). The $\mathrm{R}$ code is available on reasonable request via email to the corresponding author.

\section{Probabilities}

The model parameters were obtained from direct measurements, systematic literature reviews and metaanalyses, and the Spanish Network for the Study of Infectious Diseases imported by Travellers and Migrants $(+$ REDIVI $) .{ }^{13}$ Expert opinions were used when no other sources were found in the literature.

\section{Life-years gained}

There are no appropriate estimates of disease-adjusted life-years (DALY) or quality-adjusted life-year (QALY) weights for $S$. stercoralis infection. Previous studies have estimated QALYs by making assumptions that were logical and insightful, but still arbitrary. ${ }^{1415}$ Therefore, we used the objective measure of life-years gained (LYG) as the main outcome. With the model, the quantity of life-years for each strategy was calculated.

\section{Costs}

The cost estimates, sources, values, ranges and distributions are presented in online supplementary appendix 2 (online supplementary material). We used the pricelist of the Hospital Clinic de Barcelona, the official published costs of the National Reference Laboratory from the Instituto de Salud Carlos III, and different insurance reimbursement lists (online supplementary appendix 2). Adjustments were made to extrapolate costs to other European countries using purchasing power standards (PPS) (online supplementary appendix 2). Costs are presented as 2016 Euros (€).

Results are presented in terms of average and incremental cost-effectiveness ratios (ACERs and ICERs), measured as 2016 EUR per LYG. A strategy was considered cost-effective if the ICER was lower than the Gross Domestic Product per capita of the European Union in 2016 (EUR 32,127), the quantity selected as the willingness to pay threshold (WTP) for this analysis . ${ }^{16}$ 


\section{Data analysis}

The model was programmed in R software, V.3.4.2. ${ }^{17}$

Deterministic analysis was done with the most plausible value for each parameter. For each strategy, a one-way sensitivity analysis was undertaken, adjusting key parameters one by one according to ranges of possible values to evaluate the impact on the ACER. A probabilistic sensitivity analysis was also carried out: probability distributions were assigned to the model parameters to reflect uncertainty following guidelines. ${ }^{18}$ Because individual data were not available in most cases, the SD of each parameter was assumed to be $20 \%$ of the mean values (online supplementary appendix 2). Using 1000 Monte Carlo simulations, the ICER of the different iterations was plotted on a cost-effectiveness plane. The number of iterations to produce stable results was estimated by visual inspection of a graphic representation of the cumulative average net monetary benefits. Cost-effectiveness probability curves are also presented.

The study complied with the Consolidated Health Economic Evaluation Reporting Standards (online supplementary appendix 3, online supplementary material).

\section{Patient and public involvement}

No patients participated in the study.

\section{Role of the funding source}

This manuscript is related to the project PI17/02020 funded by the ISCIII and co-funded by the EU (FEDER). The team is partially supported by the Agència de Gestio' d'Ajuts Universitaris i deRecerca (AGAUR) (2014SGR26) and by the Tropical Disease Cooperative Research Network (RD16/0027/0004) co-funded by the
ISCIII and the EU (FEDER). The funder had no role in the study design, data collection, data analysis, data interpretation or drafting of the report. All authors had full access to all study data and had final responsibility for the decision to submit for publication.

\section{RESULTS}

\section{Study parameters}

Base-case transition probabilities are shown in table 1. The full list of probabilities, baseline values, sources, distributions and reasons of choice are shown in online supplementary appendix 1 .

The prevalence of strongyloidiasis in migrants was considered to be $12.2 \%$ (95\% CI $9.0 \%$ to $15.9 \%$ ), based on a recent systematic review and meta-analysis. ${ }^{3}$ For the baseline scenario, the healthcare seeking rate was set at 1/10,000 person-years, as reported by Valerio et al. ${ }^{19}$ For the interventions, we considered that the healthcare seeking rates reported in the Spanish national health inquiry were appropriate: for primary care, 0.78 (95\% CI 0.76 to 0.80 ); and for hospital-based interventions, 0.48 (95\% CI 0.46 to 0.50$).{ }^{20}$ The probability of being diagnosed was based on the sensitivity of the test (92\%). The same probability was considered among those who are potentially immunosuppressed since health interventions targeting those populations should be implemented before the immunosuppression is established. The prevalence of immunosuppression was considered to be $2.7 \% .^{21}$ The annual probability of developing a severe condition $(0.0423)$ was calculated by adapting the method by Freeman and Hutchison with data from the study by Salvador et al..$^{21}{ }^{22}$ To determine the effectiveness of the treatment with ivermectin, we used the results of

\begin{tabular}{|c|c|c|c|}
\hline Probabilities & Value and OWSA range & PSA distribution & Source \\
\hline $\begin{array}{l}\text { Probability of seeking outpatient } \\
\text { consultation }\end{array}$ & $\begin{array}{l}\text { Baseline: } 0.001 \\
\text { Range: } 0.009-0.0004\end{array}$ & Beta (mean 0.001, SE 0.001) & Valerio et $a l^{19}$ \\
\hline $\begin{array}{l}\text { Probability of being diagnosed and } \\
\text { treated }\end{array}$ & $\begin{array}{l}\text { Baseline: } 0.92 \\
\text { Range: } 0.969-0.877\end{array}$ & Beta (mean 0.92, SE 0.03) & Bissofi et $a l^{28}$ \\
\hline Probability of clearing infection & $\begin{array}{l}\text { Baseline: } 0.84 \\
\text { Range: } 0.72-0.98\end{array}$ & Beta (mean 0.84, SE 0.066) & $\begin{array}{l}\text { Henriquez-Camacho } \\
\text { et } a /^{6}\end{array}$ \\
\hline $\begin{array}{l}\text { Probability of seeking inpatient } \\
\text { consultation due to severe disease }\end{array}$ & $\begin{array}{l}\text { Baseline: } 0.000423 \\
\text { Range: } 0.000339-0.000508\end{array}$ & $\begin{array}{l}\text { Beta (mean } 0.000423, \text { SE } \\
0.0001)\end{array}$ & Salvador et al ${ }^{21}$ \\
\hline $\begin{array}{l}\text { Probability of being diagnosed and } \\
\text { treated for severe disease }\end{array}$ & $\begin{array}{l}\text { Baseline: } 0.92 \\
\text { Range: } 0.969-0.877\end{array}$ & Beta (mean 0.92, SE 0.03) & Bissofi et $\left.a\right|^{28}$ \\
\hline $\begin{array}{l}\text { Probability of curing and clearing } \\
\text { infection in severe disease }\end{array}$ & 1-CFR & & $\begin{array}{l}\text { CFR is estimated } \\
\text { below }\end{array}$ \\
\hline $\begin{array}{l}\text { Probability of dying due to severe } \\
\text { disease (CFR) }\end{array}$ & $\begin{array}{l}\text { Baseline: } 0.47 \\
\text { Range: } 0.33-0.62\end{array}$ & Beta (mean 0.47, SE 0.01) & Buonfrate et a $\left.\right|^{5}$ \\
\hline $\begin{array}{l}\text { Probability of misdiagnosis and } \\
\text { treatment for Strongyloides infection }\end{array}$ & $\begin{array}{l}\text { Baseline: } 0.001 \\
\text { Range: } 0.0069-0.001\end{array}$ & Beta (mean 0.001, SE 0.001) & Bissofi et $\left.a\right|^{28}$ \\
\hline Probability of death due to other causes & Mortality tables & & $\begin{array}{l}\text { Spanish National } \\
\text { Statistical Institute }\end{array}$ \\
\hline
\end{tabular}

CFR, case fatality ratio; OWSA, one-way sensitivity analysis; PSA, probabilistic sensitivity analysis. 


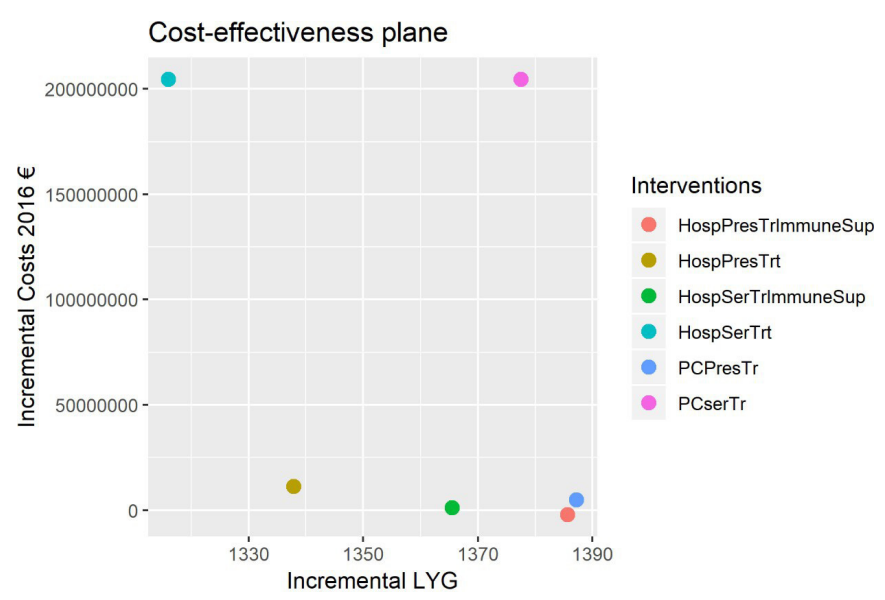

Figure 2 Cost-effectiveness plane representing the incremental costs in $2016 €$ Versus incremental effects in lifeyears gained (LYG). Hosp PresTr, hospital-based presumptive treatment; Hosp SerTr, hospital-based serology screening and treatment; HospPresTrlmmuneSup, hospital-based presumptive treatment of immunosuppressed patients; HospSerTrImmuneSup, hospital-based serology screening and treatment of immunosuppressed patients; PC PresTr, presumptive treatment at a primary care setting; PCSerTr, serology screening and treatment at a primary care setting.

the Cochrane Review by Henriquez-Camacho et al. ${ }^{6}$ The schedule was chosen as a single dose, according to the results of a recent randomised clinical trial. ${ }^{7}$ The case fatality ratio of disseminated disease was considered to be $47 \%$ (range: $33 \%-62 \%$ ). ${ }^{5}$ The mortality increase due to ivermectin in migrants from Loa loa endemic areas was $11 / 10,000 .^{29}$

Finally, pregnant women were not considered in the model since ivermectin has not been approved in this population.

\section{Base-case scenario results}

The base-case scenario (ie, no programme established) produced a total of 2,486,708.24 life-years with a cost of EUR 3,238,393.

\section{Primary care presumptive treatment}

Treating every migrant presumptively in the primary care setting yielded a total of 2,488,095.47 life-years (increase of 1387.23 LYG) at a cost of EUR 8,194,563 (increase of EUR 4,956,170), for an ACER of EUR 3573/LYG.

\section{Primary care serology and treatment}

Screening every migrant at the primary care level and then treating only those with confirmed infections yielded a total of 2,488,085.82 life-years (increase of 1377.57 LYG) at a cost of EUR 207,679,077 (increase of EUR 204,440,684). The ACER would be EUR 148,407/ LYG.

\section{Hospital-based presumptive treatment}

Treating every migrant presumptively in a hospital-based setting yielded a total of 2,488,046.17 life-years $(\Delta 1337.92$
LYG) at total cost of EUR 14,559,575 (cost increase of EUR 11,321,182). The ACER would be EUR 8462/LYG.

\section{Hospital-based serology and treatment}

Hospital-based serology and treatment yielded a total of 2,488,024.33 life-years (ie, an increase of 1316.08 lifeyears) with a cost of EUR 207,734,073 and an ACER of EUR 1,155,382/LYG.

Hospital-based presumptive treatment of immunosuppressed Presumptively treating only immunosuppressed migrants in the hospital setting yielded a total of 2,488,093.93 life-years (increase of 1385.68 LYG) at a cost of EUR $1,105,483$, resulting in a total savings of EUR 2,132,910. As this strategy was found to be cost-saving, it had a negative ICER of EUR -1539/LYG.

Hospital-based serology and treatment of immunosuppressed Screening immunosuppressed migrants and treating only those with confirmed infection in the hospital setting yielded a total of 2,488,073.8 life-years $(\Delta 1365.55$ LYG), at a cost of EUR 4,274,239, for an ACER of EUR 759/LYG.

Results of this deterministic analysis are represented in the cost-effectiveness plane in figure 2 and table 2 . PCSerTr, HospPresTr, HospSerTr and HosptSerTrim interventions dominated. The most cost-effective strategy was HospPresTrim, which was actually cost saving (ICER EUR -1539). The next most efficient strategy was PCPresTr, but compared with HospPresTrim, the ICER was far from being cost-effective (ICER EUR 4,582,464/ LYG).

\section{Sensitivity analyses}

To address parameter uncertainty, a one-way sensitivity analysis was carried out for each strategy evaluated (figure 3). The ICER of the HospPresTrim strategy remained below the cost-effectiveness threshold through the whole range of parameters.

A sensitivity analysis of structural uncertainty was undertaken, excluding the cost of the first visit in all intervention strategies based on the presumption that Strongyloides screening could be considered an opportunistic intervention as part of a consultation sought by the migrant for another reason. Therefore, visit costs were not imputed to the programme costs. Moreover, some centres routinely screen migrants for imported diseases the first time they present for consultation, so serology would simply be added. In this analysis, the HospPresTrim was the still most cost-effective strategy (ICER EUR $-1461 /$ LYG) (online supplementary appendix 4, online supplementary material)

A probabilistic sensitivity analysis was also carried out to evaluate overall uncertainty. Results are summarised in figure 4 . The strategy with the highest probability of being cost-effective was HospPresTrim, with all iterations falling below the WTP.

As there is concern about the adverse effects that could occur when presumptive ivermectin is administered to 
Table 2 Summary of the analysis results

\begin{tabular}{llclll} 
& LYG & $\begin{array}{l}\text { Lifetime costs } \\
\text { (2016 EUR) }\end{array}$ & Incremental LYG & $\begin{array}{l}\text { lncremental cost } \\
\text { (2016 EUR) }\end{array}$ & $\begin{array}{l}\text { ICER } \\
\text { (2016 EUR / } \\
\text { LYG) }\end{array}$ \\
\hline Baseline & $2,486,708.24$ & $3,238,393$ & Baseline & Baseline & Baseline \\
HospSerTr & $2,488,024.33$ & $207,734,073$ & 1316.08 & 204495681 & Dominated \\
\hline HospPresTr & $2,488,046.17$ & $14,559,575$ & 1337.92 & 11321182 & Dominated \\
\hline HospSerTrIm & $2,488,073.8$ & $4,274,239$ & 1365.55 & 1035846 & Dominated \\
\hline PCSerTr & $2,488,085.82$ & $207,679,077$ & 1377.57 & 204440684 & Dominated \\
\hline HospPresTrlm & $2,488,093.93$ & $1,105,483$ & 1385.68 & $-2,132,910^{\star}$ & $-1,539^{\star}$ \\
\hline PCPresTr & $2,488,095.47$ & $8,194,563$ & 1387.23 & 4956170 & $4,582,463.62$ \\
\hline
\end{tabular}

Dominated: the strategy is less effective and more costly.

${ }^{*}$ Cost saving.

HospPresTr, hospital-based presumptive treatment; HospPresTrlm, hospital-based presumptive treatment of immunosuppressed migrants; HospSerTr, hospital-based serology screening and treatment; HospSerTrlm, hospital-based serology screening and treatment of Immunosuppressed migrants; PCPresTr, presumptive treatment at a primary care setting; PCSerTr, serology screening and treatment at a primary care setting.

migrants infested with Loa loa (mainly severe encephalitis), a sensitivity analysis was undertaken allowing for a mortality increase in all migrants, as migrants from Loa loa-endemic countries may have a high presence in specific settings. Nevertheless, the ICER still showed cost savings (EUR -1617/LYG) (online supplementary appendix 3).

\section{DISCUSSION}

Our results show that presumptively treating immunosuppressed migrants from Strongyloides-endemic countries was the most cost-effective strategy. In fact, it saved costs compared with current clinical practice. The rest of the strategies produced a gain in life-years but were not costeffective using the chosen WTP or they were dominated (ie, they were less effective and more costly). Our findings were robust to the ranges of parameter alterations undertaken both deterministically and probabilistically.

Previous studies have evaluated different strategies in refugees to the USA, concluding that the most costeffective strategy was to perform presumptive treatment overseas. ${ }^{14} 15$ However, these studies evaluated only refugee populations in the USA, addressing mainly Asian populations, and the screening was not based on a serological test in a non-endemic setting. In our study, we decided to use serology as the only screening tool, as it is currently the most recommended strategy due to the low sensitivity of parasitological methods. In our model, we did not consider a lower sensitivity of the serological test and a lower efficacy rate in immunosuppressed migrants, ${ }^{23}$ since under ideal conditions, a screening programme would be implemented before immunosuppression is established.

Given the uncertainty in some parameters of the model, we performed a sensitivity analysis. The parameters with the highest impact were the outpatient consultation costs and hospitalisation costs. Nevertheless, presumptively treating immunosuppressed migrants remained the most cost-effective strategy.

Importantly, the prevalence of strongyloidiasis did not alter the results of any of the strategies. This is a crucial issue since changes in migratory flows could also modify the scenarios contemplated in the near term. Dynamic models that consider demographic and migration flows could therefore be a reasonable strategy for adapting the results of this study to different contexts.

A major question regarding the implementation of a Strongyloides screening programme is whether the intervention should target all migrants or just specific high-risk groups. Our results make it clear that immunosuppressed migrants should be the target population for this kind of programme. Ideally, they should be captured before immunosuppression is established. Thus, migrants that will be potentially immunosuppressed (ie, migrants diagnosed with a disease that is likely to need immunosuppressant drugs in the short or medium term, eg, steroids for chronic obstructive pulmonary disease or chemotherapy for lymphoma) should also be included.

Due to the heterogeneity of national health systems, the implementation of a presumptive programme in immunosuppressed and potentially immunosuppressed migrants could be done at different levels of care. Whereas for most national health systems, the strategy is only feasible as a hospital-based intervention, in settings with outstanding primary care programmes and trained health professionals, the strategy could be based in primary healthcare, where screening uptake is higher. ${ }^{24}$ Thus, emphasis must be placed on developing innovative and sustainable approaches to increasing the coverage of these programmes. For example, clinical decision-making tools may also be evaluated from a costeffectiveness perspective. ${ }^{25}$

In addition, serological testing is not widely available in most clinical settings yet, which is a major drawback 
A

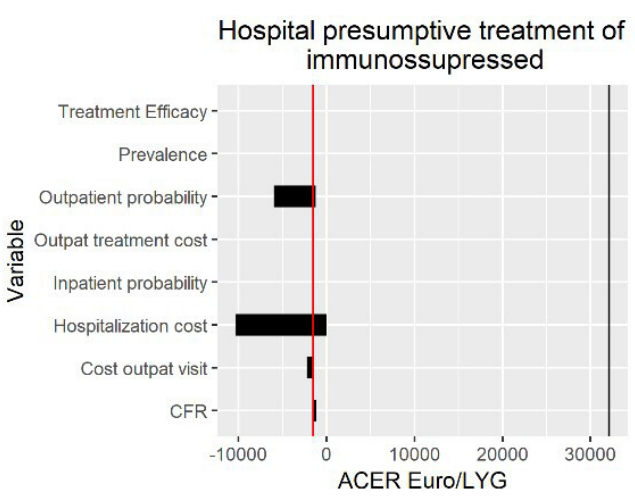

C

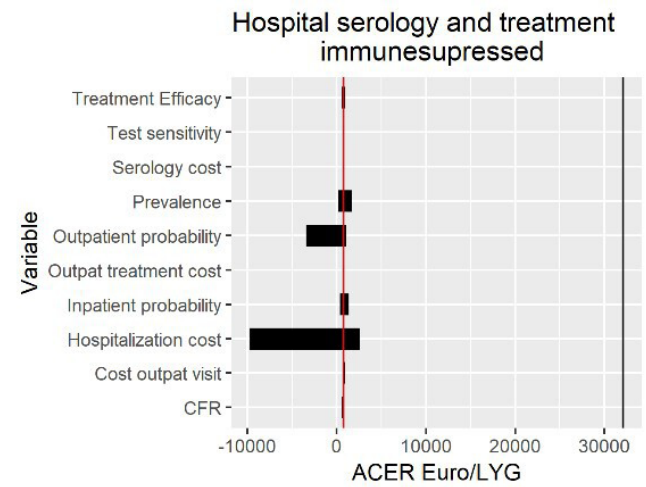

E

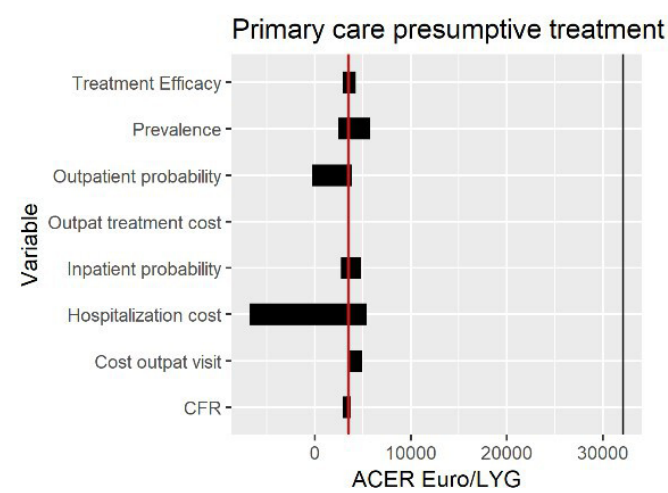

B

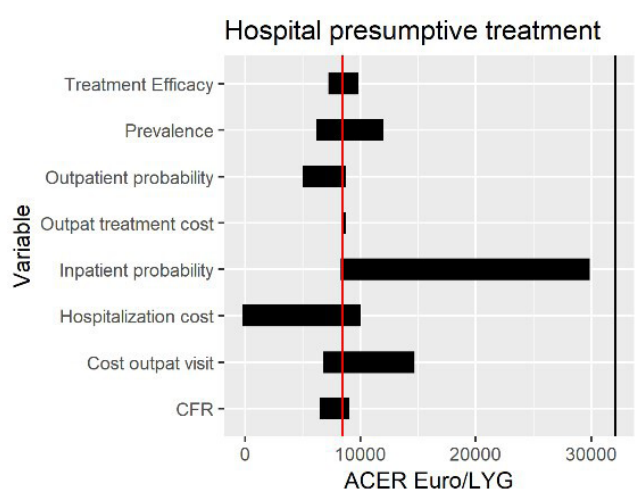

D

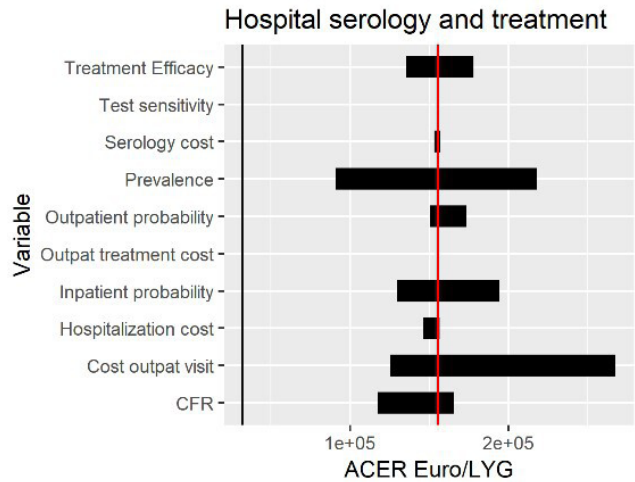

$\mathbf{F}$

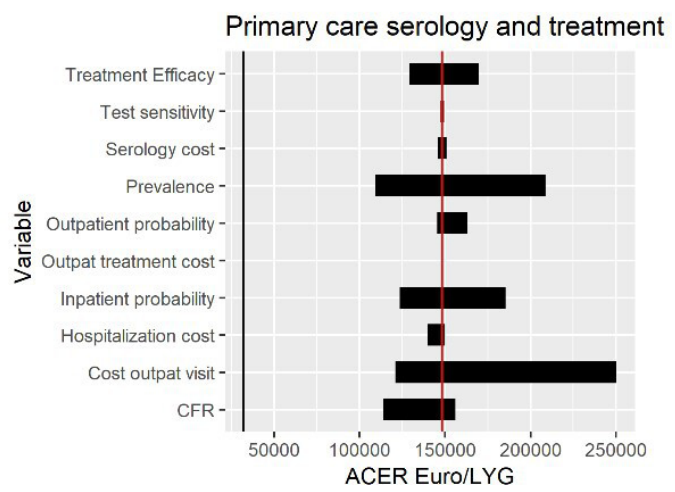

Figure 3 Tornado plots of the one-way sensitivity analysis for each strategy evaluated. Red vertical line represents the deterministic value of the ACER. The black vertical line represents the cost-effectiveness threshold. ACER, average costeffectiveness rate; CFR, case fatality ratio; LYG, life-years gained.

when considering serology screening-based strategies at both the hospital and primary care level. Developing point-of-care methods to diagnose strongyloidiasis would be highly desirable and could potentially change the scenario, making serological strategies more costeffective. Nevertheless, a presumptive treatment strategy whose target population is exclusively migrants might not be acceptable and could even be perceived as discriminatory, particularly since other screening plus treatment strategies have also been shown to be cost-effective compared with the base-case scenario. HospSerTrim, HospPresTr and PCPresTr had ACERs that fell below the
WTP, especially when the cost of the first visit was not imputed to the programme. Therefore, these interventions could be considered as alternatives if other factors preclude HospPresTrim. PCPresTr would have the benefit of avoiding the risk of disseminated disease in migrants who become immunosuppressed in the future, as well as avoiding the theoretical reintroduction of local transmission.

An important novelty of our model is that we have accounted for excess mortality in individuals with concomitant Loa loa infection, as they have a higher mortality risk when treated with ivermectin. ${ }^{26}$ Nevertheless, this 

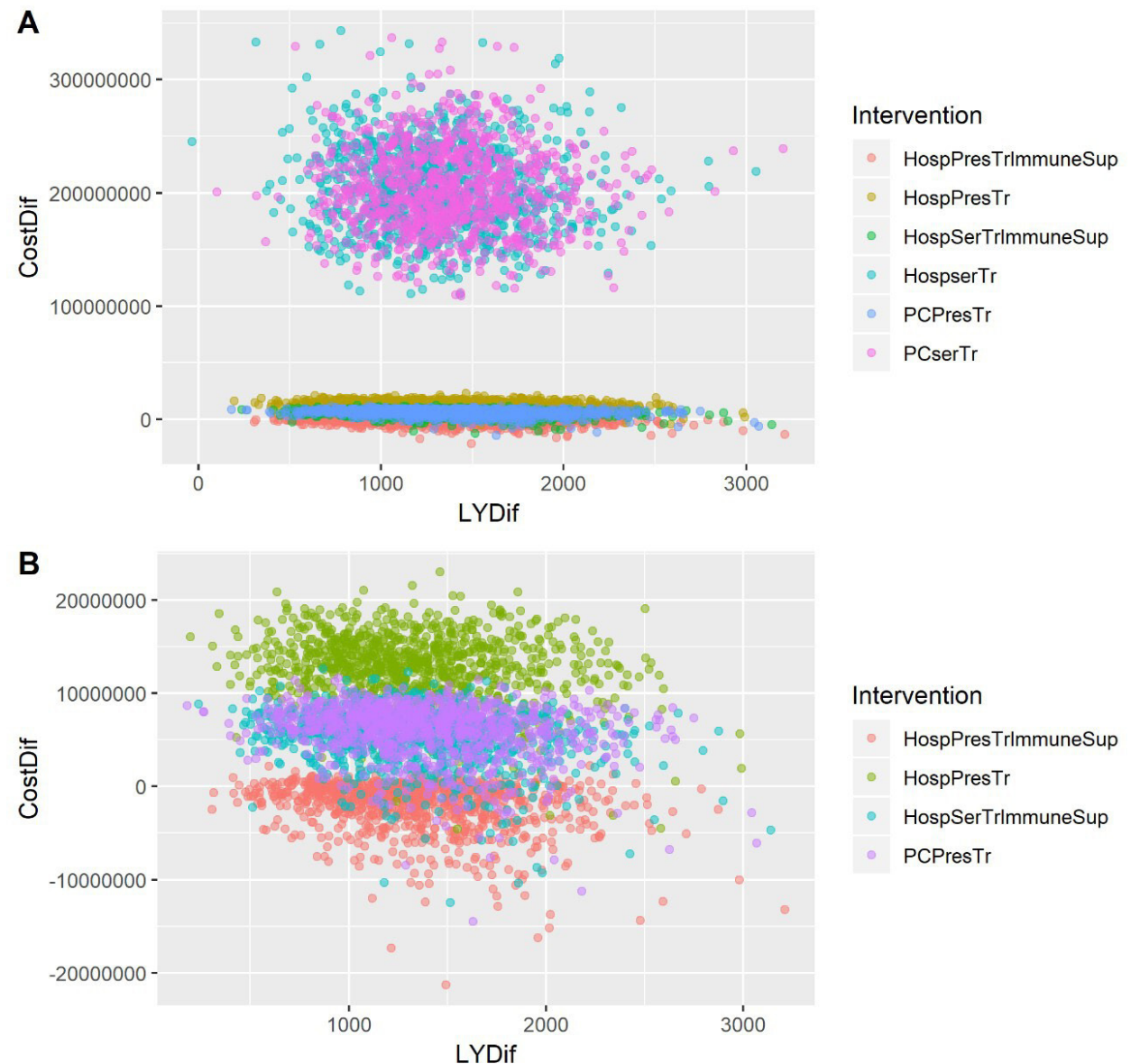

C Cost-effectiveness probability curves

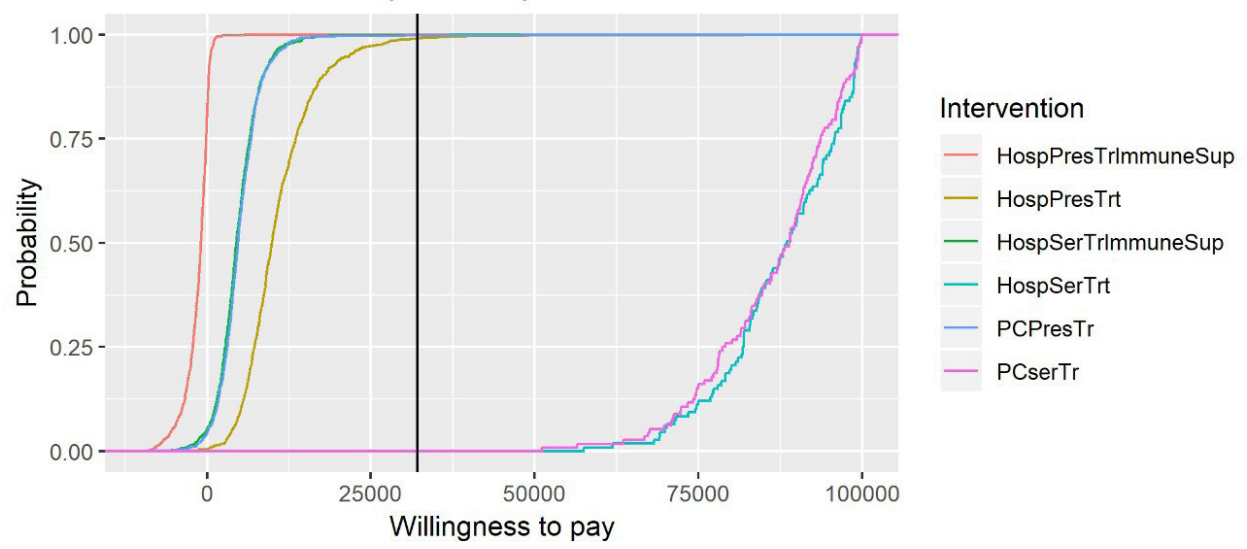

Figure 4 Probabilistic sensitivity analysis. (A) The cost-effectiveness plane is represented. (B) Cost-effectiveness plane removing the two least cost-effective strategies. (C) Cost-effectiveness probability curves. Hosp PresTr, hospital-based presumptive treatment; Hosp SerTr, hospital-based serology screening and treatment; HospPresTrlmmuneSup, hospitalbased presumptive treatment of immunosuppressed patients; HospSerTrlmmuneSup, hospital-based serology screening and treatment of immunosuppressed patients; PC PresTr, presumptive treatment at a primary care setting; PCSerTr, serology screening andtreatment at a primary care setting.

mortality increase is not very high $(0.0011)$ Therefore, presumptive treatment did not have an important impact on LYG. However, when implementing this kind of programme in clinical practice, this potentially severe side effect should be avoided, particularly if Loa loa infection can be easily ruled out.

On the other hand, presumptive treatments cannot estimate cases and treatment failures of the drug, and ivermectin is not easily accessible in European countries. Therefore, implementing a presumptive treatment programme could entail supply side problems. This possibility should be evaluated locally. However, pharmaceutical companies and European regulatory bodies have recently launched initiatives to increase the production of ivermectin and market it in EU countries, and we hope these results will encourage such endeavours. 
Another major question is the kind of immunosuppression that poses the highest risk for severe strongyloidiasis. Further studies should evaluate and quantify the risk of progression to severe disease, depending on the level of immunosuppression. This knowledge would allow for a more targeted screening intervention, prioritising clinical units or patients at high risk.

Our study has several limitations. The model has not been prospectively validated and relies on a series of assumptions. We did not account for the possibility of local transmission, as it was considered non-existent, with a highly unlikely risk for reintroduction. Some of the parameters used for the model have a high degree of uncertainty. Another limitation is that there are no estimates for DALYs in S. stercoralis infection. Therefore, we used the objective measure of LYG. Nevertheless, this parameter does not account for quality of life and imposes a limitation on the results of our study. While chronic Strongyloides infection is not considered to substantially reduce quality of life, very few good quality studies have been published so far on its clinical burden, so this is an issue that undoubtedly needs further investigation. ${ }^{27}$

\section{CONCLUSIONS}

Presumptively treating for $S$. stercoralis infection in all immunosuppressed migrants from Strongyloides endemic countries seems to be a cost-saving strategy. Our findings provide an important basis to support the implementation of presumptive treatment programmes. However, other factors should also be considered, such as the heterogeneity of health system characteristics as well as the acceptability of this strategy, particularly in individuals at higher risk of developing severe side effects.

\author{
Author affiliations \\ ${ }^{1}$ Medicina Interna, Hospital Universitari San Juan de Alicante, San Juan de Alicante, \\ Alicante, Spain \\ ${ }^{2}$ Foundation for the Promotion of the Research in Healthcare and Biomedicine, \\ Valencia, Spain \\ ${ }^{3}$ Medicina Interna/Enfermedades Infecciosas, Hospital Vega Baja-FISABIO, San \\ Bartolome-Orihuela, Alicante, Spain \\ ${ }^{4}$ Clinical Medicine, Universidad Miguel Hernandez de Elche Facultad de Medicina, \\ Sant Joan D'Alacant, Spain \\ ${ }^{5}$ Public Health, Karolinska Institutet, Stockholm, Stockholm County, Sweden \\ ${ }^{6}$ ISGlobal, Barcelona, Catalunya, Spain \\ ${ }^{7}$ Infectious Tropical Diseases and Microbiology, IRCCS Sacro Cuore Don Calabria \\ Hospital, Negrar, Veneto, Italy \\ ${ }^{8}$ Diagnostics and Public Health, University of Verona, Verona, Veneto, Italy \\ ${ }^{9}$ Instituto de Salud Global Barcelona, Barcelona, Spain \\ ${ }^{10}$ Division of Infectious Diseases, Department of Medicine-Solna, Karolinska \\ Institutet, Stockholm, Sweden
}

Contributors PEW-J: study design, analysis execution, interpretation, manuscript drafting. JL-G: study design, results interpretation, manuscript supervision and review. JS: study design, analysis supervision, results interpretation, manuscript review. JG: analysis interpretation, manuscript review. JM: study design, manuscript review. ZB: results interpretation, manuscript review. AR-M: study design, analysis supervision, results interpretation, manuscript supervision and review.

Funding Tropical Disease Cooperative Research Network and Agència de Gestió d'Ajuts Universitaris i de Recerca.

Competing interests None declared.
Patient and public involvement Patients and/or the public were not involved in the design, conduct, reporting or dissemination plans of this research.

Patient consent for publication Not required.

Provenance and peer review Not commissioned; externally peer reviewed.

Data availability statement All data relevant to the study are included in the article or uploaded as supplementary information.

Open access This is an open access article distributed in accordance with the Creative Commons Attribution Non Commercial (CC BY-NC 4.0) license, which permits others to distribute, remix, adapt, build upon this work non-commercially, and license their derivative works on different terms, provided the original work is properly cited, appropriate credit is given, any changes made indicated, and the use is non-commercial. See: http://creativecommons.org/licenses/by-nc/4.0/.

ORCID iD

Philip Erick Wikman-Jorgensen http://orcid.org/0000-0002-6329-0311

\section{REFERENCES}

1 Olsen A, van Lieshout L, Marti H, et al. Strongyloidiasis--the most neglected of the neglected tropical diseases? Trans $R$ Soc Trop Med Hyg 2009;103:967-72.

2 Bisoffi Z, Buonfrate D, Montresor A, et al. Strongyloides stercoralis: a plea for action. PLoS Negl Trop Dis 2013;7:e2214-10.

3 Asundi A, Beliavsky A, Liu XJ, et al. Prevalence of strongyloidiasis and schistosomiasis among migrants: a systematic review and meta-analysis. Lancet Glob Health 2019;7:e236-48.

4 Requena-Méndez A, Chiodini P, Bisoffi Z, et al. The laboratory diagnosis and follow up of strongyloidiasis: a systematic review. PLoS Negl Trop Dis 2013;7:e2002.

5 Buonfrate D, Requena-Mendez A, Angheben A, et al. Severe strongyloidiasis: a systematic review of case reports. BMC Infect Dis 2013;13:78.

6 Henriquez-Camacho C, Gotuzzo E, Echevarria J, et al. Ivermectin versus albendazole or thiabendazole for Strongyloides stercoralis infection. Cochrane Database Syst Rev 2016;2.

7 Buonfrate D, Salas-Coronas J, Muñoz J, et al. Multiple-Dose versus single-dose ivermectin for Strongyloides stercoralis infection (strong treat 1 to 4): a multicentre, open-label, phase 3, randomised controlled superiority trial. Lancet Infect Dis 2019;19:1181-90.

8 Requena-Mendez A, Buonfrate D, Bisoffi Z, et al. Advances in the diagnosis of human strongyloidiasis. Curr Trop Med Rep 2014;1:207-15.

9 Gómez-Junyent J, Paredes-Zapata D, de las Parras ER, et al. Real-Time polymerase chain reaction in stool detects transmission of Strongyloides stercoralis from an infected donor to solid organ transplant recipients. Am J Trop Med Hyg 2016;94:897-9.

10 Agbata EN, Morton RL, Bisoffi Z, et al. Effectiveness of screening and treatment approaches for schistosomiasis and strongyloidiasis in newly-arrived migrants from endemic countries in the EU/EEA: a systematic review. Int J Environ Res Public Health 2019;16:1-41.

11 European Centre for Disease Prevention and Control. Public health guidance on screening and vaccination for infectious diseases in newly arrived migrants within the EU/EEA. Stockholm 2018.

12 Tan-Torres T, Baltussen R, Adam T, et al. Guide to cost effectiveness analysis. Geneva, 2003. http://www.who.int/choice/ publications/p_2003_generalised_cea.pdf

13 Pérez-Molina JA, López-Polín A, Treviño B, et al. 6-Year review of +Redivi: a prospective registry of imported infectious diseases in Spain. J Travel Med 2017;24:1-7.

14 Muennig P, Pallin D, Sell RL, et al. The cost effectiveness of strategies for the treatment of intestinal parasites in immigrants. $N$ Engl J Med 1999;340:773-9.

15 Maskery B, Coleman MS, Weinberg M, et al. Economic analysis of the impact of overseas and domestic treatment and screening options for intestinal helminth infection among US-Bound refugees from Asia. PLoS Negl Trop Dis 2016;10:e0004910-4.

16 European Union GDP per capita | 1960-2018 | data | chart | calendar. Available: https://tradingeconomics.com/european-union/gdp-percapita [Accessed 7 Sep 2018].

17 R Core Team. R: a language and environment for statistical computing, 2015. Available: https://www.r-project.org/

18 Briggs $\mathrm{AH}$, Weinstein MC, Fenwick EAL, et al. Model parameter estimation and uncertainty analysis: a report of the ISPOR-SMDM modeling good research practices Task force working Group-6. Med Decis Making 2012;32:722-32. 
19 Valerio L, Roure S, Fernández-Rivas G, et al. Strongyloides stercoralis, the hidden worm. epidemiological and clinical characteristics of 70 cases diagnosed in the North metropolitan area of Barcelona, Spain, 2003-2012. Trans R Soc Trop Med Hyg 2013;107:465-70.

20 INEbase / Sociedad /Salud /Encuesta nacional de salud / Resultados, 2017. Available: https://www.ine.es/dyngs/INEbase/ es/operacion.htm?c=Estadistica_C\&cid=1254736176783\&menu= resultados\&idp $=1254735573175$ [Accessed 6 Mar 2019].

21 Salvador F, Treviño B, Chamorro-Tojeiro S, et al. Imported strongyloidiasis: data from 1245 cases registered in the +REDIVI Spanish collaborative network (2009-2017). PLoS Negl Trop Dis 2019;13:e0007399.

22 Freeman J, Hutchison GB. Prevalence, incidence and duration. Am J Epidemiol 1980;112:707-23.

23 Luvira V, Trakulhun K, Mungthin M, et al. Comparative diagnosis of strongyloidiasis in immunocompromised patients. Am J Trop Med Hyg 2016;95:401-4.
24 Seedat F, Hargreaves S, Nellums LB, et al. How effective are approaches to migrant screening for infectious diseases in Europe? A systematic review. Lancet Infect Dis 2018;18:e259-71.

25 Sequeira-Aymar E, diLollo X, Osorio-Lopez Y, et al.

[Recommendations for the screening for infectious diseases, mental health, and female genital mutilation in immigrant patients seen in Primary Care]. Aten Primaria 2020;52:193-205.

26 Gardon J, Gardon-Wendel N, et al. Serious reactions after mass treatment of onchocerciasis with ivermectin in an area endemic for Loa loa infection. Lancet 1997;350:18-22.

27 Tamarozzi F, Martello E, Giorli G, et al. Morbidity Associated with Chronic Strongyloides stercoralis Infection: A Systematic Review and Meta-Analysis. Am J Trop Med Hyg 2019;100:1305-11.

28 Bisoffi Z, Buonfrate D, Sequi M, et al. Diagnostic accuracy of five serologic tests for Strongyloides stercoralis infection. PLoS Negl Trop Dis 2014;8:38.

29 de EIN. Tablas de mortalidad de la población de España. Serie:1975-2015. 